\title{
The CS1 segment of fibronectin is involved in human OSCC pathogenesis by mediating OSCC cell spreading, migration, and invasion
}

\author{
Pachiyappan Kamarajan', Angeles Garcia-Pardo², Nisha J D'Silva' and Yvonne L Kapila*1
}

\begin{abstract}
Background: The alternatively spliced V region or type III connecting segment III (IIICS) of fibronectin is important in early development, wound healing, and tumorigenesis, however, its role in oral cancer has not been fully investigated. Thus, we investigated the role of CS-1, a key site within the CSIII region of fibronectin, in human oral squamous cell carcinoma (OSCC).

Methods: To determine the expression of CS-1 in human normal and oral SCC tissue specimens immunohistochemical analyses were performed. The expression of CS1 was then associated with clinicopathological factors. To investigate the role of CS-1 in regulating OSCC cell spreading, migration and invasion, OSCC cells were assayed for spreading and migration in the presence of a CS-1 peptide or a CS-1 blocking peptide, and for invasion using Matrigel supplemented with these peptides. In addition, integrin a4siRNA or a focal adhesion kinase (FAK) anti-sense oligonucleotide was transfected into OSCC cells to examine the mechanistic role of integrin a4 or FAK in CS1-mediated cell spreading and migration, respectively.

Results: CS-1 expression levels were significantly higher in OSCC tissues compared to normal tissues $(p<0.05)$. Also, although, high levels of CS-1 expression were present in all OSCC tissue samples, low-grade tumors stained more intensely than high grade tumors. OSCC cell lines also expressed higher levels of CS-1 protein compared to normal human primary oral keratinocytes. There was no significant difference in total fibronectin expression between normal and OSCC tissues and cells. Inclusion of CS-1 in the in vitro assays enhanced OSCC cell spreading, migration and invasion, whereas the CS1 blocking peptide inhibited these processes. Suppression of integrin a4 significantly inhibited the CS1-mediated cell spreading. Furthermore, this migration was mediated by focal adhesion kinase (FAK), since FAK suppression significantly blocked the CS1-induced cell migration.
\end{abstract}

Conclusion: These data indicate that the CS-1 site of fibronectin is involved in oral cancer pathogenesis and in regulating OSCC cell spreading, migration and invasion.

\section{Background}

Oral squamous cell carcinoma is the most common type of oral cancer accounting for almost $90 \%$ of all oral malignancies, and it continues to have a poor 5 year survival rate [1]. Improved survival can only result from scientific advances and a better understanding of risk factors associated with the disease. Identification of specific molecules associated with malignant transformation has led to the identification of an increasing number of molecular

\footnotetext{
* Correspondence: ykapila@umich.edu

1 Department of Periodontics and Oral Medicine, School of Dentistry, University of Michigan, Ann Arbor, Michigan 48109-1078, USA Full list of author information is available at the end of the article
}

markers that are related to tumor stage and grading and may have a prognostic value for the disease [2]. Significant knowledge has also been gained about key molecules that regulate the cell cycle, apoptosis, immunologic tumor defense, and extracellular matrix interactions and breakdown in oral cancer [3-6].

One such extracellular matrix molecule important in tumorigenesis and in cell differentiation, proliferation, migration, and survival is fibronectin [7]. Fibronectin is a ubiquitous protein present in tissues and body fluids, including plasma that engages in these cellular functions and provides architectural scaffolding for cells and tis- 
sues. The fibronectin gene contains three separate exons that undergo alternative splicing, to yield the ED-A, ED-B and IIICS/V regions (Figure 1A) [8]. The presence of additional acceptor and donor splice signals within the IIICS region allows generation of multiple IIICS polypeptide variants, namely, three in rat fibronectin [8,9] and five in human fibronectin [10,11], thus increasing fibronectin diversity. One subset of these molecular variants expresses a 25 amino acid sequence within the IIICS region termed CS1 isoform or CS1 site, $[12,13]$ which is a counter-receptor for the $\alpha 4 \beta 1$ (VLA4) integrin $[14,15]$. The CS1 site mostly mediates adhesion of lymphoid cells and some tumor cells [13,14]. Another cell adhesive site is located within the carboxyl-terminal 31 residues of IIICS and it is referred to as CS5. The adhesive activity of CS5 is much weaker than that of CS1 [13]. Thus, in addition to the classical $\alpha 5 \beta 1$ fibronectin receptor, which recognizes the Arg-Gly-Asp sequence within fibronectin, the CS1 region functions as an alternative cell attachment site for certain cell types $[16,17]$.

The alternatively spliced segments of fibronectin are thought to play a role in embryonic development, wounding healing, and tumorigenesis [18-20]. However, to our knowledge a comparative study of the role of the CS1 site of fibronectin in oral squamous cell carcinomas (OSCC) of various grades combined with in vitro analyses of its function have not yet been conducted. A limited study of 10 OSCC tissue specimens detected CS-1 expression by RT-PCR in these tissues, but significant correlations did not emerge likely due to the limited sample size [21]. In the present investigation, we performed a comparative analysis of CS1 expression patterns on OSCCs with different tumor grades. In vitro examination of the role of CS1 in OSCC cell spreading, migration, and invasion was

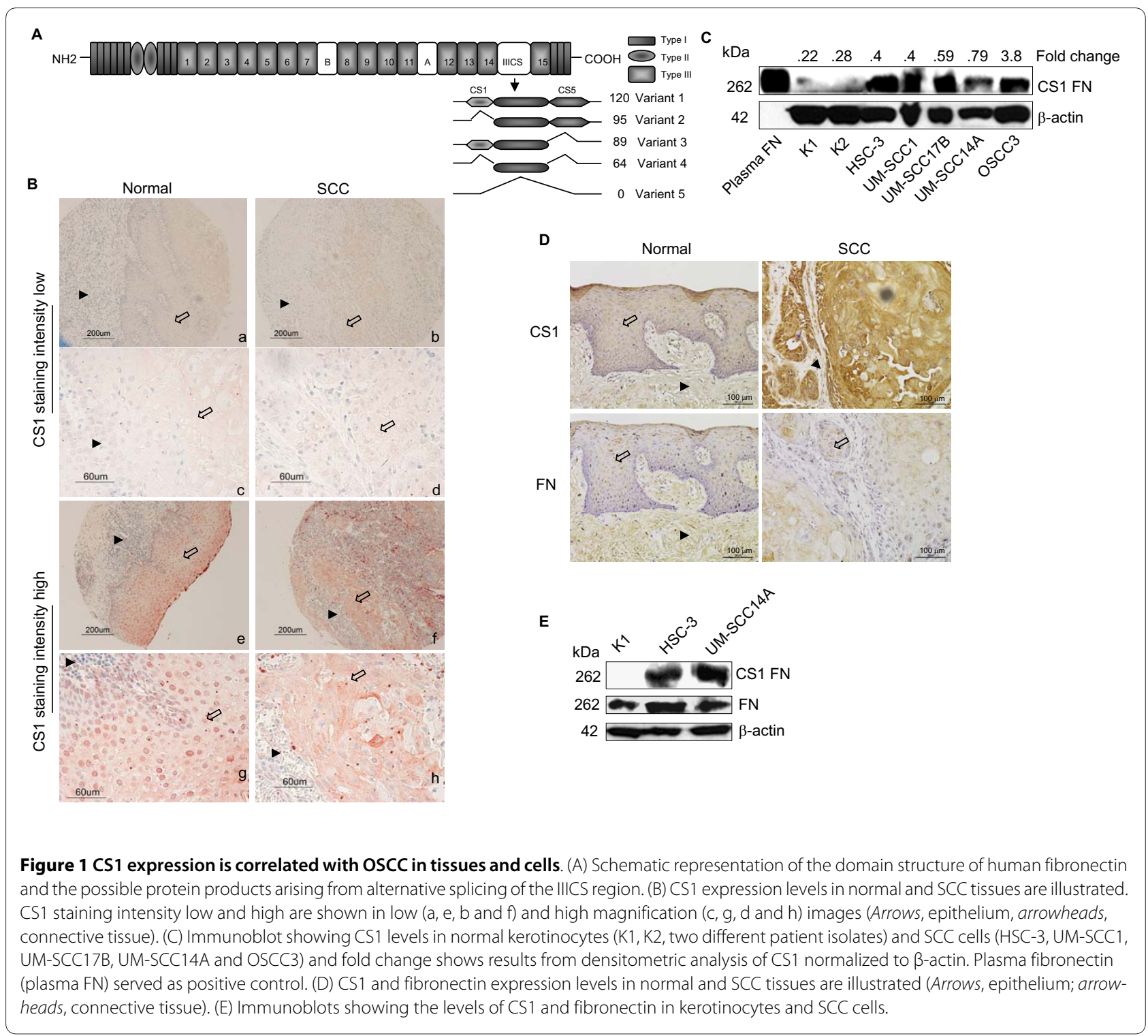


also performed. We demonstrate that the expression of the alternatively spliced CS1 site is associated with OSCC tumorigenesis as it is highly expressed in low grade tumors. These data therefore indicate that the CS-1 fibronectin site may play an important role in the pathology of OSCC.

\section{Methods}

\section{Cell lines and peptides}

The highly invasive human oral SCC cell line HSC-3 (tongue) [22] was kindly provided by Randy Kramer (University of California, San Francisco). The human oral SCC cell lines, UM-SCC-1 (floor of mouth), UM-SCC17B (larynx), and UM-SCC-14A (floor of mouth) were gifts from Tom Carey (University of Michigan, Ann Arbor). The poorly differentiated aggressive tongue SCC cell line OSCC-3 was gift from Mark Lingen (University of Chicago, Chicago). Primary human oral keratinocytes were derived from normal gingival tissues discarded following periodontal surgical procedures, as approved by the University of Michigan IRB. OSCC cells were maintained in a $5 \% \mathrm{CO}_{2}$ atmosphere at $37^{\circ} \mathrm{C}$ in DMEM (Gibco) supplemented with $10 \%$ fetal bovine serum, 1\% penicillin, and $1 \%$ streptomycin. CS-1 peptide (EILDVPST) (H-2094) and CS-1 blocking peptide (VLA4 inhibitor, Phenyllac-Leu-Asp-Phe-D-Pro-NH $\left.{ }_{2}\right)(\mathrm{H} 3376)$ were purchased from Bachem. CS1 blocking peptide blocks the binding of the very late antigen (VLA4) integrin to fibronectin. Control scrambled peptide, Scr1 $(\mathrm{H}-$ Ser-Ile-Glu-Leu-Thr-Pro-Val-Ala-OH) or Scr2 (H-SerIle-Glu-Leu-Thr-Pro-Val-Asp-OH) was synthesized by the Protein Structure Facility, University of Michigan. Primary oral keratinocytes were maintained in Epilife media.

\section{Peptide conjugation to BSA}

Synthetic peptides were chemically conjugated to BSA using glutaraldehyde (GA) (Sigma) as the cross linker and these were prepared by the Protein Structure facility, University of Michigan. Briefly, BSA (10 mg/ml) was dissolved in conjugation buffer and mixed with GA to a concentration of $1.25 \%$. After overnight incubation at room temperature, unreacted GA was removed by gel filtration on a G-25 sephadex column. The activated BSA (2 $\mathrm{ml}$ GA-BSA $)$ was then added to peptides $[(5 \mathrm{mg} / \mathrm{ml}$; Scr, CS1 and CS1 Blocking peptide (VLA4 inhibitor)] and incubated at room temperature for $1 \mathrm{~h}$ and overnight at $4^{\circ} \mathrm{C}$. Free peptides were removed by dialysis against $0.1 \mathrm{M}$ PBS overnight at $4^{\circ} \mathrm{C}$. The concentration of final conjugates was estimated based on BSA concentration.

\section{Tissues and Tissue Microarrays}

Immunohistochemical analysis was performed to determine the expression of CS-1 in human normal and OSCC tissue specimens (Tissue microarrays, OR601 Biomax.us and HN241, Accumax) using the histostatin kit (95-6143, Zymed lab) as per the manufacturer's instructions. In addition, 5 representative tissue samples of OSCC and 5 normals were obtained from tissue core facility, University of Michigan and Accumax (HN241) for CS1 and fibronectin expression. Briefly, after antigen retrieval by microwave pretreatment (citrate buffer, $10 \mathrm{mM}, \mathrm{pH}$ 6.0), slides were incubated with a CS1 primary antibody (P1F11) [23] or fibronectin (clone 2Q604, Santa Cruz Biotechnology) overnight at $4^{\circ} \mathrm{C}$. For negative controls, slides were incubated with mouse IgG as the primary antibody. After diaminobenzidine chromogen (DAB) reaction, slides were counterstained with routine hematoxylin. Immunohistochemical staining for CS-1 grading was evaluated and scored by a pathologist in a blinded manner.

\section{Immunoblot analysis}

For immunoblot analysis, cells were lysed in RIPA lysis buffer containing protease inhibitors $(50 \mathrm{mM}$ Tris/ $/ \mathrm{HCl}$, pH 7.4, $1 \%$ Nonidet P-40, $0.25 \%$ sodium deoxycholate, $150 \mathrm{mM} \mathrm{NaCl}, 1 \mathrm{mM}$ EGTA, $1 \mathrm{mM}$ PMSF, $1 \%$ protease inhibitor cocktail (P8340, Sigma), $1 \mathrm{mM} \mathrm{Na}_{3} \mathrm{VO}_{4}$, and 1 $\mathrm{mM} \mathrm{NaF}$ ) on ice for $30 \mathrm{~min}$. Proteins were resolved by SDS-PAGE, transferred to Immobilon-P membranes (Millipore) and blots were probed with antibodies to CS1 fibronectin (clone P1F11, Chemicon), fibronectin (H300, Santa Cruz Biotechnology), FAK (clone 2A7, Upstate Biotech) or $\beta$-actin (clone C-11, Santa Cruz Biotechnology). The antigen and antibody complexes were developed with the ECL-Plus detection system (Pierce). All other reagents were from Sigma.

\section{Cell spreading assay}

Briefly, $1 \times 10^{4}$ cells were re-suspended in $100 \mu \mathrm{l}$ serum free DMEM containing the scrambled peptide, CS1 peptide or CS1 blocking peptide. Cells were then plated in a 96 well plate, and incubated at $37^{\circ} \mathrm{C}$ in a humidified 5\% $\mathrm{CO} 2$ incubator for $3 \mathrm{~h}$. The assay measuring cell spreading on immobilized peptides was carried out as described $[12,13]$. Briefly, BSA conjugated peptides (Scr-BSA, CS1BSA and CS1 blocking-BSA (VLA4 inhibitor) were diluted to various concentrations in PBS and $100 \mu \mathrm{l}$ aliquots were added to 96 well plates. Peptides were allowed to adsorb overnight at $37^{\circ} \mathrm{C}$, and then nonspecific binding sites were blocked with $10 \mathrm{mg} / \mathrm{ml} \mathrm{BSA}$ in PBS for $1 \mathrm{~h}$. Cells were plated at $1 \times 10^{4}$ cells/well in $100 \mu \mathrm{l}$ of serum free DMEM and then incubated at $37^{\circ} \mathrm{C}$ in a humidified $5 \% \mathrm{CO} 2$ incubator for $3 \mathrm{~h}$. In another experiment, cells were transfected with integrin $\alpha 4$ siRNA (100 pM, Ambion) for $36 \mathrm{~h}$ and then plated in 96 well plates. Cell spreading was assessed under the microscope and by 
photography. The percentage of cell spreading was calculated using NIS-Elements BR-3.0 imaging software.

\section{Migration assay}

Migration assays were performed as previously described [24]. Cells grown overnight were wounded uniformly using plastic pipette tips, and cultured for $16 \mathrm{~h}$ in the presence of scrambled CS1 peptide, CS1 peptide or CS1 blocking peptide. In another experiment, cells were transfected with control oligonucleotides or FAK anti-sense oligonucleotides (Oligos Etc) [25] and incubated with CS1 peptide for $16 \mathrm{~h}$. Standard photographs were taken of the wounded areas using NIS-Elements BR-3.0 imaging software. The cell migration distance was calculated by subtracting the distance at the lesion edge at $16 \mathrm{~h}$ from the distance measured at $0 \mathrm{~h}$.

\section{Matrigel invasion assay}

Briefly, transwell inserts with $8 \mu \mathrm{M}$ pores (Becton Dickinson) were coated $50 \mu \mathrm{l}$ matrigel (BD Matrigel?, BD Biosciences). Cells at $1 \times 10^{6}$ were seeded in the upper chambers with $100 \mu \mathrm{l}$ of serum free medium. Serum free medium $(650 \mu \mathrm{l})$ supplemented with scrambled peptide or various concentrations of CS1 peptide were placed in the lower chambers and incubated at $37^{\circ} \mathrm{C}$ for $24 \mathrm{~h}$. Cells that invaded the matrigel-coated membrane and emerged on the underside surface of the membrane were labeled with Calcein AM fluorescent dye (BD Biosciences) as per the manufacturer's instructions. Fluorescence intensity was read at 485/520 in a fluorescence spectrophotometer (SPECTRA max M2, Molecular Devices) and reported as fold change in invasion relative to a media control.

\section{Statistical analysis}

In general, values are expressed as means \pm SD. Intergroup differences were determined by two-way analysis of variance (ANOVA) and Scheffe's multiple-comparison test. Statistical significance was defined as ${ }^{*}$, ${ }^{*} \mathrm{p} \leq 0.05$. For tissue microarray analysis a chi-square test was employed. All experiments were repeated in triplicate.

\section{Results}

\section{CS1 expression is correlated with OSCC}

To examine CS1 expression in OSCCs, immunohistochemical analyses were performed using tissue microarrays of OSCCs. A total of 80 samples, 63 malignant and 17 normal tissues, from 52 males and 28 female patients were analyzed. The age range of the patients was 21 to 80 years. Tumors of grade I to IV from the tongue, cheek, gingiva, lip and oral mucosa were analyzed and compared to normal tissue from similar anatomical locations.

Examples of tissue microarray staining for CS-1 protein expression in OSCCs and normal tissue samples that exhibited high and low level staining are represented (Figure 1B). Normal epithelium expressed nuclear and cytoplasmic staining, whereas cancer cells expressed cytoplasmic staining. The staining intensity was assessed as low or high. CS1 expression levels were significantly higher in OSCC tissues compared to normal tissues (Table 1, p < 0.03). Also, although, all levels of CS-1 expression were present in the various OSCC tissue samples (Table 1), low grade tumors (Group I) stained at a higher level of intensity compared to that of high grade tumors (Group II) $(\mathrm{p}<0.01)$. Furthermore, CS1 staining

\section{Table 1: Correlation of CS1 containing fibronectin expression and clinicopathological variables in normal and oral SCC} tissues

\begin{tabular}{|c|c|c|c|c|}
\hline & \multirow[t]{2}{*}{ No. of tissue specimens } & \multicolumn{2}{|c|}{ CS1 staining intensity [No. of tissue specimens(\%)] } & \multirow[t]{2}{*}{$P$ value } \\
\hline & & Low & High & \\
\hline Normal & 17 & $9(53)$ & $8(47)$ & \\
\hline Tumor & 63 & $15(24)$ & $48(76)$ & Normal vs Tumor $0.03^{*}$ \\
\hline \multicolumn{5}{|l|}{ Tumor grade vs CS1 staining } \\
\hline Group-I (I,I-II and II)a & 49 & $8(16)$ & $41(84)$ & \\
\hline Group-II (II-III, III and IV) a & 14 & $7(50)$ & $7(50)$ & Group I vs Group II 0.01* \\
\hline \multicolumn{5}{|l|}{ Organ vs CS1 staining } \\
\hline Normal & 8 & $4(50)$ & $4(50)$ & \\
\hline \multicolumn{5}{|l|}{ Tongue } \\
\hline Tumor & 26 & $7(24)$ & $19(76)$ & Normal vs Tumor $0.05^{*}$ \\
\hline Tongue & & & & \\
\hline
\end{tabular}

aparenthetical data under tumor grade vs CS1 staining denote original tumor grade provided in tumor microarray. These grades were pooled into groups for purposes of statistical analysis.

Statistical analysis: Chi-square test; ${ }^{*}$ significant difference $p \leq 0.05$ 
intensity was significantly higher for the tongue samples from OSCCs compared to the normal tissues ( $\mathrm{p}<0.05)$. Importantly, there were significant differences in CS1, but not in total fibronectin expression between normal and SCC tissues (Figure 1D). Comparisons between age or gender and CS1 staining did not show any significant correlations. Other organ specific comparisons were not possible because of low sample size.

To further validate the importance of CS1 in OSCC, CS1 expression was examined in several human OSCC cell lines and normal primary human oral keratinocytes. Similar to the tissue microarray staining pattern, OSCC cells expressed higher levels of CS1 compared to the normal primary keratinocytes (Figure $1 \mathrm{C}$ ). There was no significant difference between OSCC cells and primary keratinocytes in fibronectin levels (Figure 1E).

\section{CS1 mediates OSCC cell spreading}

To determine the contribution of the IIICS (V) region of fibronectin, especially of the CS1 site to attachment and spreading of human OSCC cells, we measured the effect of a peptide containing the CS1 sequence on these processes. CS1 promoted OSCC cell spreading in a dosedependent manner compared to a scrambled CS1 peptide control or media control. Spreading was robust with 80 $\mu \mathrm{g} / \mathrm{ml}$ of CS1 in both cell lines (Figure 2A and 2B top panel). In contrast, the CS1 blocking peptide (VLA4 inhibitor) abrogated OSCC cell spreading. To further confirm the ability of CS1 peptides to mediate spreading, OSCC cells were plated onto surfaces coated with immobilized peptides coupled with BSA. Under these conditions, significant cell spreading was again observed in CS1-BSA coated wells compared to those coated with Scr-BSA, and CS1 blocking peptide-BSA (VLA4 inhibitor) inhibited OSCC spreading (Figure $2 \mathrm{C}$ top panel). Thus, CS1 promotes cell spreading in OSCC cells. The percentage of OSCC cell spreading under these different conditions was quantified and illustrated (Figure 2A, B and $2 \mathrm{C}$ bottom panel). Since integrin $\alpha 4$ is a counterreceptor for CS1 we examined the role of integrin $\alpha 4$ in OSCC cell spreading. Suppression of integrin $\alpha 4$ with siRNA significantly inhibited the CS1-mediated cell spreading (Figure 2D).

\section{CS1 promotes human OSCC cell migration and invasion}

Next we investigated whether CS1 is involved in migration of OSCC cells using wound-healing assays. In the presence of CS1, OSCC cells exhibited increased migration compared to controls (Figure 3A middle panel). In contrast, the CS1 blocking peptide (VLA4 inhibitor) abrogated OSCC cell migration compared to CS1 treated samples and controls (Figure 3A bottom panel). A scrambled peptide for CS1 did not influence the migration more than that of control cells incubated in media alone
(Figure 3A top panel). The percentage of OSCC cell migration under these different conditions was quantified and illustrated (Figure 3B and 3C).

To assess downstream signaling in CS1 induced migration, we investigated the role of FAK in OSCC cells. In CS1 treated cells, FAK phosphorylation at Tyr-925 increased (Figure 3D top left panel). Furthermore, this migration is mediated by focal adhesion kinase (FAK), since FAK suppression significantly blocked the CS1induced cell migration (Figure 3D bottom panel). The percentage of OSCC cell migration under these different conditions was quantified and illustrated (Figure 3E).

To explore the ability of CS1 to modulate cell invasion by OSCC cells, matrigel invasion assays was performed. These assays showed that CS1 significantly increased the invasiveness of OSCC cells in a dose-dependent manner, unlike the media or scrambled CS1 peptide controls (Figure 3F). Altogether our results show that CS1 promotes OSCC cell migration and invasion.

\section{Discussion}

The present study was performed to evaluate the significance of the CS1 site of fibronectin in OSCC pathogenesis. CS1 has been previously associated with increased cell adhesion in human lymphoma, rhabdomyosarcoma, and mouse melanoma cells [26]. Although the physiological significance of the molecular diversity of fibronectin at its three variable regions (ED-A, ED-B and IIICS) remains poorly understood, several lines of evidence indicate that splicing variations at the IIICS region modulate the adhesive and migrating properties of cells [13,16,27]. However, none of the studies reported to date have explored the role of the CS1 site in OSCC pathogenesis. Our data showed that alternative splicing of the IIICS region of fibronectin was deregulated in oral cancer tissues with a significant increase in the CS1 isoform. The importance of CS1 in tumorigenesis emerged from the tissue microarray data showcasing a statistically significant opposite relationship of staining intensity for CS1 between OSCC and normal oral tissues. There was no significant difference in total fibronectin expression between normal and OSCC tissues. The higher level of CS1 staining exhibited by most of the OSCC tissues in contrast to the lower level of staining in the normal tissues and its cytoplasmic preferential localization supports a role for CS1 in OSCC pathogenesis. Also, although, all levels of CS-1 expression were present in the various OSCC tissue samples, low-grade tumors stained at a higher level of intensity compared to that of high grade tumors, suggesting that CS1 is involved in the early stages of tumorigenesis. Higher CS1 protein expression but not total fibronectin levels in OSCC cell lines compared to primary keratinocytes further validated the importance of CS1 in this process. Other investigators 


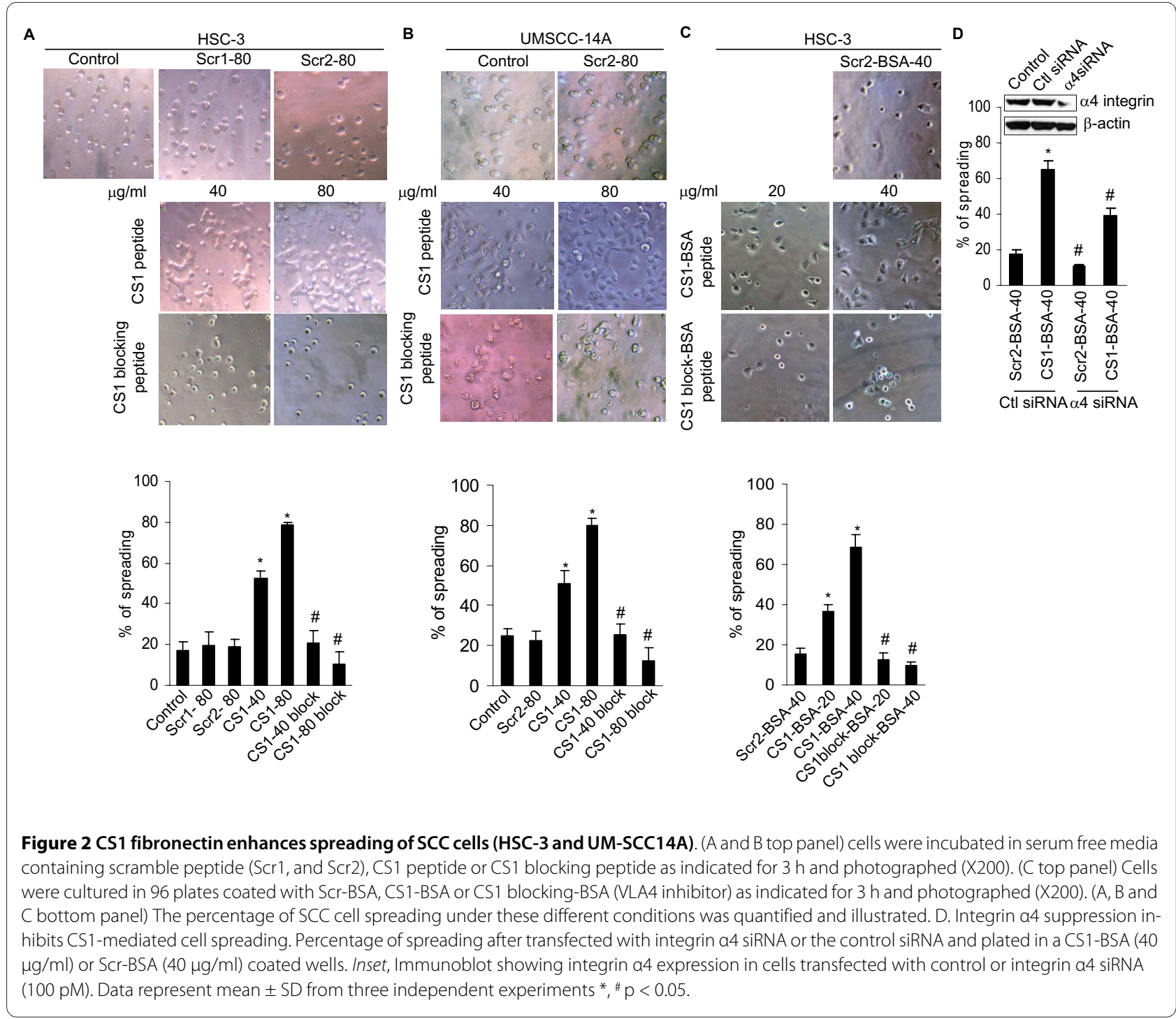

have shown that the relative abundance of fibronectin mRNA containing the CS1 sequence was significantly increased in both fetal and cancerous liver tissue, although it was not altered in non-malignant tissues derived from chronic hepatitis and cirrhosis patients [28]. Furthermore, the CS1 peptide increases cell adhesion of human epithelial carcinoma (A431) [29] and leukemic monocyte lymphoma cells (U937), and a CS1 blocking peptide (VLA4 inhibitor) or $\alpha 4 \beta 1$ function-blocking monoclonal antibodies inhibited cell adhesion and invasion by U937 and lung tumor cells $[17,30]$. In addition, CS1 isoforms are present on the synovial endothelium of rheumatoid arthritis patients, and adhesion of T lymphoblastoid cells to this endothelium could be abrogated by an anti- $\alpha 4$ integrin antibody or by a synthetic CS1 peptide (VLA4 inhibitor) [31]. Further, our findings suggest that CS1-mediated cell adhesion in OSCC cells was regulated by integrin $\alpha 4$. Indeed, we have previously shown these OSCC cells express the VLA4 receptor, which therefore can enable interactions via CS1 [25,32].

Cell migration is essential for invasion and metastasis of cancer cells [33]. It involves the assembly and disassembly of focal adhesion complexes. These integrinlinked complexes are the primary sites of adhesion between cells and the surrounding extracellular matrix [34]. FAK plays a central role in the turnover of these adhesion sites [35]. FAK controls the dynamic process of integrin-linked adhesions and is an important regulator of cell migration. Increased FAK expression and activity are frequently correlated with malignant or metastatic disease and poor patient prognosis [36-39]. Previously we demonstrated that an altered fibronectin matrix induces anoikis of human squamous cell carcinoma cells by suppressing phosphorylation of FAK and ERK [25]. Our present results, which show that FAK suppression blocks CS1-mediated OSCC cell migration, further supports the 


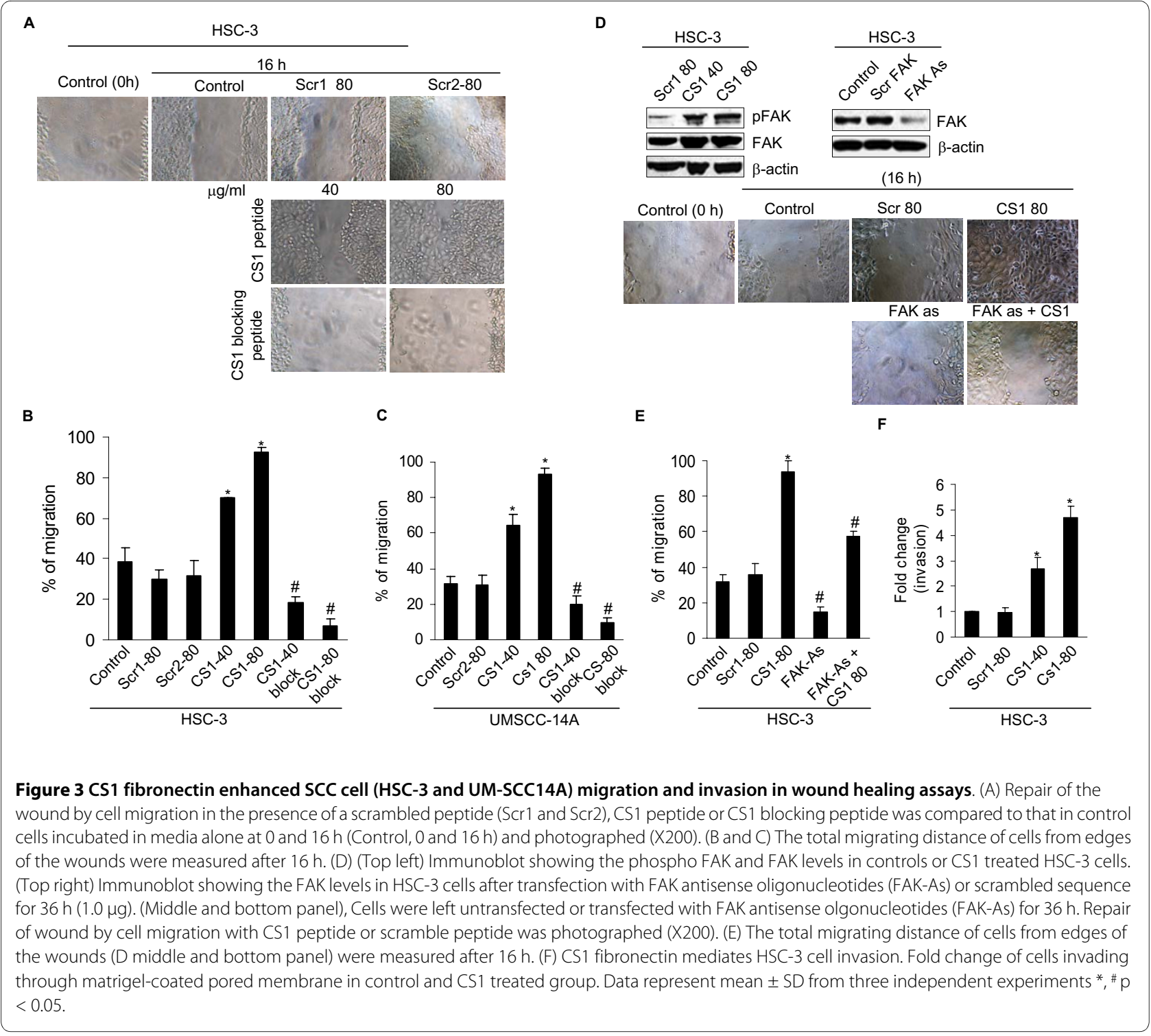

concept that CS1 promotes OSCC cell adhesion and migration in a FAK rich environment, and this may contribute to tumorigenesis.

\section{Conclusions}

In summary, our data suggest that the increased expression of CS1 by OSCC cells may, in the early stages of pathogenesis, facilitate the local migration and invasion of these cells into the surrounding extracellular matrix to become locally aggressive.

\section{Competing interests}

The authors declare that they have no competing interests.

\section{Authors' contributions}

PK designed the study and performed experiments and wrote the manuscript APG provided critical comments and suggested revisions of the manuscript. NJD coordinated the pathology components of the study. YLK interpreted the data and wrote the manuscript. All authors read and approved the final manuscript.

\section{Acknowledgements}

We thank Dr. Sindhu Halubai for performing the statistical analyses, and Thomas E. Carey, Mark W. Lingen and Randy Kramer for gifts of reagents. This work was supported by Grant R01 DE014429 from the National Institutes of Health to Yvonne L. Kapila and AGP was supported by grant SAF2009-07035 from the Ministerio de Ciencia e Innovacion, Spain.

\section{Author Details}

'Department of Periodontics and Oral Medicine, School of Dentistry, University of Michigan, Ann Arbor, Michigan 48109-1078, USA and 2Cellular and Molecular Medicine Program, Centro de Investigaciones Biologicas, CSIC, Madrid, Spain

Received: 20 August 2009 Accepted: 25 June 2010

Published: 25 June 2010 


\section{References}

1. Bsoul SA, Huber MA, Terezhalmy GT: Squamous cell carcinoma of the oral tissues: a comprehensive review for oral healthcare providers. J Contemp Dent Pract 2005, 6(4):1-16.

2. Schliephake H: Prognostic relevance of molecular markers of oral cancer--a review. Int J Oral Maxillofac Surg 2003, 32(3):233-245.

3. Scully C, Field JK, Tanzawa H: Genetic aberrations in oral or head and neck squamous cell carcinoma (SCCHN): 1. Carcinogen metabolism, DNA repair and cell cycle control. Oral Oncol 2000, 36(3):256-263.

4. Tralongo V, Rodolico V, Luciani A, Marra G, Daniele E: Prognostic factors in oral squamous cell carcinoma. A review of the literature. Anticancer Res 1999, 19(4C):3503-3510

5. Thomas GJ, Speight PM: Cell adhesion molecules and oral cancer. Crit Rev Oral Biol Med 2001, 12(6):479-498.

6. Ziober BL, Silverman SS Jr, Kramer RH: Adhesive mechanisms regulating invasion and metastasis in oral cancer. Crit Rev Oral Biol Med 2001, 12(6):499-510.

7. Kosmehl H, Berndt A, Katenkamp D: Molecular variants of fibronectin and laminin: structure, physiological occurrence and histopathological aspects. Virchows Arch 1996, 429(6):311-322.

8. Schwarzbauer JE, Tamkun JW, Lemischka IR, Hynes RO: Three different fibronectin mRNAs arise by alternative splicing within the coding region. Cell 1983, 35(2 Pt 1):421-431.

9. Tamkun JW, Schwarzbauer JE, Hynes RO: A single rat fibronectin gene generates three different mRNAs by alternative splicing of a complex exon. Proc Natl Acad Sci USA 1984, 81(16):5140-5144.

10. Vibe-Pedersen K, Magnusson S, Baralle FE: Donor and acceptor splice signals within an exon of the human fibronectin gene: a new type of differential splicing. FEBS Lett 1986, 207(2):287-291.

11. Hershberger RP, Culp LA: Cell-type-specific expression of alternatively spliced human fibronectin IIICS mRNAs. Mol Cell Biol 1990, 10(2):662-671.

12. Humphries MJ, Akiyama SK, Komoriya A, Olden K, Yamada KM: Identification of an alternatively spliced site in human plasma fibronectin that mediates cell type-specific adhesion. J Cell Biol 1986, 103(6 Pt 2):2637-2647.

13. Humphries MJ, Komoriya A, Akiyama SK, Olden K, Yamada KM: Identification of two distinct regions of the type III connecting segment of human plasma fibronectin that promote cell type-specific adhesion. J Biol Chem 1987, 262(14):6886-6892.

14. Wayner EA, Garcia-Pardo A, Humphries MJ, McDonald JA, Carter WG Identification and characterization of the T lymphocyte adhesion receptor for an alternative cell attachment domain (CS-1) in plasma fibronectin. J Cell Biol 1989, 109(3):1321-1330.

15. Guan JL, Hynes RO: Lymphoid cells recognize an alternatively spliced segment of fibronectin via the integrin receptor alpha 4 beta 1. Cell 1990, 60(1):53-61.

16. Dufour S, Duband JL, Humphries MJ, Obara M, Yamada KM, Thiery JP: Attachment, spreading and locomotion of avian neural crest cells are mediated by multiple adhesion sites on fibronectin molecules. EMBO J 1988, 7(9):2661-2671.

17. Saiki I, Murata J, Makabe T, Matsumoto Y, Ohdate Y, Kawase Y, Taguchi Y, Shimojo T, Kimizuka F, Kato I, et al: Inhibition of lung metastasis by synthetic and recombinant fragments of human fibronectin with functional domains. Jpn J Cancer Res 1990, 81(10):1003-1011.

18. Jarnagin WR, Rockey DC, Koteliansky VE, Wang SS, Bissell DM: Expression of variant fibronectins in wound healing: cellular source and biological activity of the EIIIA segment in rat hepatic fibrogenesis. J Cell Biol 1994, 127(6 Pt 2):2037-2048.

19. Ffrench-Constant C, Van de Water L, Dvorak HF, Hynes RO: Reappearance of an embryonic pattern of fibronectin splicing during wound healing in the adult rat. J Cell Biol 1989, 109(2):903-914.

20. Tavian D, De Petro G, Colombi M, Portolani N, Giulini SM, Gardella R, Barlati S: RT-PCR detection of fibronectin EDA + and EDB + mRNA isoforms: molecular markers for hepatocellular carcinoma. Int J Cancer 1994, 56(6):820-825

21. Mighell AJ, Thompson J, Hume WJ, Markham AF, Robinson PA: RT-PCR investigation of fibronectin mRNA isoforms in malignant, normal and reactive oral mucosa. Oral Oncol 1997, 33(3):155-162.

22. Matsumoto K, Nakamura T, Kramer RH: Hepatocyte growth factor/ scatter factor induces tyrosine phosphorylation of focal adhesion kinase ( $\mathrm{p} 125 \mathrm{FAK})$ and promotes migration and invasion by oral squamous cell carcinoma cells. J Biol Chem 1994, 269(50):31807-31813.

23. Garcia-Pardo A, Sanchez-Aparicio P, Wayner EA: Two novel monoclonal antibodies to fibronectin that recognize the Hep II and CS-1 regions respectively: their differential effect on lymphocyte adhesion. Biochem Biophys Res Commun 1992, 186(1):135-142.

24. Kapila YL, Niu J, Johnson PW: The high affinity heparin-binding domain and the $\mathrm{V}$ region of fibronectin mediate invasion of human oral squamous cell carcinoma cells in vitro. J Biol Chem 1997, 272(30):18932-18938

25. Kamarajan $\mathrm{P}$, Kapila YL: An altered fibronectin matrix induces anoikis of human squamous cell carcinoma cells by suppressing integrin alpha v levels and phosphorylation of FAK and ERK. Apoptosis 2007 12(12):2221-2231

26. Maeda T, Oyama R, Titani K, Sekiguchi K: Engineering of artificial celladhesive proteins by grafting EILDVPST sequence derived from fibronectin. J Biochem 1993, 113(1):29-35.

27. Kocher O, Kennedy SP, Madri JA: Alternative splicing of endothelial cell fibronectin mRNA in the IIICS region. Functional significance. Am J Pathol 1990, 137(6):1509-1524.

28. Oyama F, Hirohashi S, Sakamoto M, Titani K, Sekiguchi K: Coordinate oncodevelopmental modulation of alternative splicing of fibronectin pre-messenger RNA at ED-A, ED-B, and CS1 regions in human liver tumors. Cancer Res 1993, 53(9):2005-2011.

29. Hashino $K$, Matsushita $H$, Kato I: Effects of fibronectin fragments on DNA transfection into mammalian cells by electroporation. J Biochem 1997. 122(3):490-493.

30. Katoh K, Mohri H, Ogawa K, Okubo T: Human Plasma Fibronectin Mediates Adhesion of U937 Cells by RGD and CS1. J Thromb Thrombolysis 1998, 5(2):125-134.

31. Elices MJ, Tsai V, Strahl D, Goel AS, Tollefson V, Arrhenius T, Wayner EA Gaeta FC, Fikes JD, Firestein GS: Expression and functional significance of alternatively spliced CS1 fibronectin in rheumatoid arthritis microvasculature. J Clin Invest 1994, 93(1):405-416.

32. Zhang $Y, L u H$, Dazin $P$, Kapila Y: Functional differences between integrin alpha4 and integrins alpha5/alphav in modulating the motility of human oral squamous carcinoma cells in response to the $V$ region and heparin-binding domain of fibronectin. Exp Cell Res 2004, 295(1):48-58.

33. Gassmann P, Enns A, Haier J: Role of tumor cell adhesion and migration in organ-specific metastasis formation. Onkologie 2004, 27(6):577-582.

34. Burridge K, Chrzanowska-Wodnicka M: Focal adhesions, contractility, and signaling. Annu Rev Cell Dev Biol 1996, 12:463-518.

35. McLean GW, Carragher NO, Avizienyte E, Evans J, Brunton VG, Frame MC: The role of focal-adhesion kinase in cancer - a new therapeutic opportunity. Nat Rev Cancer 2005, 5(7):505-515

36. Owens LV, Xu L, Craven RJ, Dent GA, Weiner TM, Kornberg L, Liu ET, Cance WG: Overexpression of the focal adhesion kinase (p125FAK) in invasive human tumors. Cancer Res 1995, 55(13):2752-2755.

37. Cance WG, Harris JE, lacocca MV, Roche E, Yang X, Chang J, Simkins S, Xu L: Immunohistochemical analyses of focal adhesion kinase expression in benign and malignant human breast and colon tissues: correlation with preinvasive and invasive phenotypes. Clin Cancer Res 2000 6(6):2417-2423

38. Recher C, Ysebaert L, Beyne-Rauzy O, Mansat-De Mas V, Ruidavets JB, Cariven P, Demur C, Payrastre B, Laurent G, Racaud-Sultan C: Expression of focal adhesion kinase in acute myeloid leukemia is associated with enhanced blast migration, increased cellularity, and poor prognosis. Cancer Res 2004, 64(9):3191-3197.

39. Schlaepfer DD, Mitra SK, Ilic D: Control of motile and invasive cell phenotypes by focal adhesion kinase. Biochim Biophys Acta 2004, 1692(2-3):77-102

Pre-publication history

The pre-publication history for this paper can be accessed here: http://www.biomedcentral.com/1471-2407/10/330/prepub

doi: $10.1186 / 1471-2407-10-330$

Cite this article as: Kamarajan et al., The CS1 segment of fibronectin is involved in human OSCC pathogenesis by mediating OSCC cell spreading, migration, and invasion BMC Cancer 2010, 10:330 